\title{
Learning from a deceptively spacious policy discourse
}

\author{
Sarah Hayes \\ Centre for Learning, Innovation and Professional Practice, Aston University, s.hayes@aston.ac.uk
}

\begin{abstract}
Networked Learning, e-Learning and Technology Enhanced Learning have each been defined in different ways, as people's understanding about technology in education has developed. Yet each could also be considered as a terminology competing for a contested conceptual space. Theoretically this can be a 'fertile trans-disciplinary ground for represented disciplines to affect and potentially be re-orientated by others' (Parchoma and Keefer, 2012), as differing perspectives on terminology and subject disciplines yield new understandings. Yet when used in government policy texts to describe connections between humans, learning and technology, terms tend to become fixed in less fertile positions, linguistically. A deceptively spacious policy discourse that suggests people are free to make choices conceals an economically-based assumption that implementing new technologies, in themselves, determines learning. Yet it actually narrows choices open to people as one route is repeatedly in the foreground and humans are not visibly involved in it. An impression that the effective use of technology for endless improvement is inevitable cuts off critical social interactions and new knowledge for multiple understandings of technology in people's lives. This paper explores some findings from a corpus-based Critical Discourse Analysis of UK policy for educational technology during the last 15 years, to help to illuminate the choices made. This is important when through political economy, hierarchical or dominant neoliberal logic promotes a single 'universal model' of technology in education, without reference to a wider social context (Rustin, 2013). Discourse matters, because it can 'mould identities' (Massey, 2013) in narrow, objective economically-based terms which 'colonise discourses of democracy and student-centredness' (Greener and Perriton, 2005:67). This undermines subjective social, political, material and relational (Jones, 2012: 3) contexts for those learning when humans are omitted. Critically confronting these structures is not considered a negative activity. Whilst deterministic discourse for educational technology may leave people unconsciously restricted, I argue that, through a close analysis, it offers a deceptively spacious theoretical tool for debate about the wider social and economic context of educational technology. Methodologically it provides insights about ways technology, language and learning intersect across disciplinary borders (Giroux, 1992), as powerful, mutually constitutive elements, ever-present in networked learning situations. In sharing a replicable approach for linguistic analysis of policy discourse I hope to contribute to visions others have for a broader theoretical underpinning for educational technology, as a developing field of networked knowledge and research (Conole and Oliver, 2002; Andrews, 2011).
\end{abstract}

\section{Keywords}

Networked Learning, e-Learning, Technology Enhanced Learning, policy, Critical Discourse Analysis

\section{Introduction}

Networked Learning, e-learning and Technology Enhanced Learning are all terms that might further a critical theoretical debate about the needs of education. Yet in policy discourse they have mostly served as static markers to maintain a particular and dominant, economically-based world view of educational technology, which distorts ideas of networked learning communities (Greener and Perriton, 2005:67). Networked Learning is understood 'to promote connections: between one learner and other learners, between learners and tutors; between a learning community and its learning resources (Goodyear, et al., 2004:1) and as such is 'relational' between all of these things (Jones, 2012: 3). In contrast in policy we find an underlying assumption that implementing new technologies, in themselves, determines learning. Though hardly a new argument this deterministic approach is framed within both hierarchical and broader neoliberal (Campbell and Pedersen 2001; Harvey 2005) policies for education. Both forms of economic policy have dominated language with strong capitalist values. I demonstrate through UK discourse how 'policy continuities' (Ball, 1999) continue to affect how people identify the role of technology economically in learning. Greener and Perriton drew attention to a meeting of political economy with e-learning. Distinguishing between hierarchical 'Keynesian' forms of educational delivery that others have called a 'paternalist vision of education' (Conlon, 2000: 111), and a 'Schumpeterian' entrepreneurial market-driven model, they described how utopian rhetoric can mask other 
societal issues in networked learning (Greener and Perriton, 2005:69). I will refer to these extremes of policy for educational provision as either hierarchical or neoliberal, though neither economic theory will be discussed in detail in this paper, as the focus is on how these play out in the discourse.

There are indeed those who perceive the current global economic crisis to have reached such a depth now as to transcend the limitations of conventional economic thinking. The consequent need for radical rethinking means no longer a continuation of 'existing assumptions under a different name' (Hall, Massey, and Rustin, 2013). It is from this point of departure that I discuss how a related instrumental vocabulary in policy texts that tends to reflect consumer culture and self-interest (Massey, 2013) has moulded narrow conceptions of technology-based learning for too long. This is a discourse that positions technology (by any name), as the main driver of social change, and ultimately as the driver of how people learn. What this viewpoint often omits however are the complex political, social and economic factors that bring technologies into being and that serve to support a particular power and culture. Even more of concern is a trend towards omitting people altogether.

In 2002 Chris Jones raised the question: is there a policy for networked learning? This same question might have been asked repeatedly since then about e-learning or Technology Enhanced Learning, and similar conclusions could be drawn:-

Choices about how to use new technologies need to be infused with a more sharply critical edge. One that begins by asking what social interests are driving the agenda that hides behind the technology and that begins to map out alternative visions of technological possibilities more centred in the needs of education and learning' (Jones, 2002)

In over a decade since, much has happened to further ideas for open education, as new technological platforms and human social networks have developed. Yet, in another sense, little has changed to provide us with a coherent and fertile theoretical space for educational technology policy development. There has, for example, been a new name provided for our practice every few years that is said to have 'subsumed' the previous one:-

E-learning is starting to subsume and replace a number of previously used terms such as communications and information technologies (C\&IT or ICT), information and learning technologies (ILT), networked learning, telelearning or telematics and instructional technology (Edgehill Strategy, 2005)

The concept of e-learning is thus becoming subsumed into a wider discussion of how learning can be enhanced by more effective and far-reaching uses of digital technologies (JISC, 2009)

The move from 'e-learning' to 'enhancing learning through the use of technology' is now well embedded and recognised (JISC, 2012)

One might argue that in simply changing the terminology it is rather like papering over the cracks in a sub standard property. To do a thorough job we would consider the structure and base (Marx, 1867), and work from there to change the whole space to become more habitable to accommodate a diversity of theory and practice. In a fertile discursive environment there is room for all of these terms to be explored, defined and developed, rather than to assume one concept must 'subsume' the others. There is though a tendency in government policy language to tidy and order ways of building knowledge into linear processes, detached chunks of learning and neat parcels of practice. The real human labour actions can get pushed aside in a quest to tell people positivesounding outcomes from certain approaches towards technologies. People may not 'believe' these 'operational' concepts, but they can be justified in 'getting the job done' (Marcuse, 1964). I propose a closer examination of some constraints in policy language that hinder development of a 'sharply critical edge' (Jones, 2002) to debates about educational technology. It is a deceptively spacious language that has promised much in terms of flexibility and tailoring for individual students (Greener and Perriton, 2005:72), yet this notion is promulgated through reference to 'the student experience' as something singular and universal, not subjective and relational, as shown in the examples below, whether discussing e-learning, or Technology Enhanced Learning (TEL):

Raise the profile of examples of TEL for enhancement of the student experience and to save staff time. (University of Westminster TEL Strategy 2008-2011)

Provide a valid mechanism for the recognition of excellence in the use and implementation of e-

Proceedings of the 9th International Conference on Networked Learning 2014, Edited by: Bayne S, Jones C, de Laat M, Ryberg T \& Sinclair C.
ISBN 978-1-86220-304-4 
learning to enhance the student experience.

(University of Huddersfield E-Learning Strategy 2008-2013)

Choices made in language to express ideas about technology in education frequently remain unquestioned because they are framed in a simplified notion of 'common sense' (Gramsci, 1971) Confronting these structures draws attention to the fact that the language of competitive economic markets is not the only way to discuss educational technology. It has simply been the dominant one and it can be changed by a networked learning community. To strengthen and re-build this structural base, it is necessary to critically acknowledge the complexities of discourse, as social practice that connects technology, language and learning. From here we might seek a more critical, theoretical and 'fertile trans-disciplinary ground' (Parchoma and Keefer, 2012).

\section{Economically useful knowledge}

To contribute to this vision I draw on a constant from Marxist theory. This is the need to 'examine the relationship between the capitalist mode of production and the specific problem' (Greener and Perriton, 2005:69) to uncover the underlying power dynamics. In general, policy discourse has taken as its point of departure a single argument that technology, as an external solution, might be applied to learning, to guarantee something additional and useful in return. The 'exchange value' gained may be the promise of a greater performance, a competitive edge, or additional skills, as a form of 'capital' (Marx, 1867). However, to choose other routes, where 'economically useful knowledge' (Jessop, 2008:4) is not the primary concern, is almost not considered a choice at all (Dahlberg, 2004). Whether technology can improve efficiency is not called into question in this study. Instead the more pressing problem is raised that this economical feature alone should be considered representative of the diverse possibilities for human learning, as a connection with technology and other people, across multiple networks of human and non-human actors (Latour, 1992). Instrumental and deterministic principles still seem to constitute the broader base of government policy discourse for educational technology, and thus determine much of the strategy within the superstructure of our educational systems. There is a danger though that a base structure of economic policy supports a compressed version of how students might experience technology, language and learning. Deceptively spacious language can marginalise dialectical realities of material connections (Sorensen, 2009: 193) for individual learning. In short, the political discourse seems to disjoin people, from the material practice of learning with technology.

New forms of technological practice now take place in universities. However, to assume a direct link with learning, beyond an increase in productivity, misses out the question of how technology actually yields an increase in knowledge, as a process of inquiry and critique. Understanding enhancement too, only in terms of additional value, is restrictive, if technologies can extend us (McLuhan, 2005) to overcome endless limitations. We might consider that 'everything is technology' (Braudel, 1985), when all around us, it shapes our history, knowledge and individual lives. We in turn shape it, in multiple ways (Wajcman, 2002). 'Things' of all types form repositories of, and for, our learning, construct our social worlds (Sezneva, 2007) and contain 'traces' of us (Lash, 2002). Given these broader understandings, human pedagogical interactions with technologies across space and time are far from simply enhanced, irrespective of the claims of government policies.

Closely linked to both technology and learning, is the language people use to describe their interactions with technological knowledge. How people talk and write about technology, more specifically, educational technology reveals the values they apply to it (Feenberg, 2003; Fairclough, 2007). Yet, for understanding language, humans have developed terms that distinguish different aspects. Discourse is the 'in use' element of language and, as such, is a broad concept, because it co-evolves with all other elements it touches in society. For technology, there are less adequate terms for its heterogeneous and temporal qualities and our own levels of understanding. It presents a problem for learning though, if in policy language, the cultural and political elements of technological knowledge cease to exist, and technology means only constant improvement.

\section{A trans-disciplinary methodology in corpus-based CDA}

In a trans-disciplinary approach I link critical social theory about technology, language and learning with a corpus-based Critical Discourse Analysis (CDA) of UK policy texts for educational technology between 1997 and 2012. A corpus is the name given to a collection, or bank of texts gathered for analysis. Understanding a corpus of words as 'net-like' (Hoey, 1991) and reflective of the 'concerns of the society which produces the 
texts’ (Hunston, 2002:13) is helpful in order to visualise a fluid interplay of the elements of technology and learning within the language of policy. In a quantitative analysis of patterns of discourse, I examined through corpus linguistics (Scott, 1997, Baker, 2006) 2.5 million words of UK policy. 'Use' was one of the top word count frequencies, appearing 8131 times in the whole corpus. I chose to focus on these 8131 instances of 'use' to examine more closely the way that technology and other words cluster around 'use'. 'Technology' appeared 6079 times, 'the use of' 1770 times and 'use of technology' 350 times. Below in Figure 1 a few lines of text show a small section of a pattern that was often repeated, with 'effective use of' actually appearing 185 times.

models of good e-learning practice Develop the effective use of technology to enable and support work-based learning Explore and support $t$ Irity of the data held to support service delivery. Effective use of technology can help deliver more secure and more joined-up public services Ind staff development, helping institutions make effective use of technology for teaching and learning, research, administration, marketing an ə resources that were identified confirm that the effective use of technology to enhance assessment for learning as well as the assessment । earners in a cohesive way, making efficient and effective use of technology to support academic, social and pastoral activity. Using open so IISC has had an important role in promoting the effective use of technology in the area of staff development and the role ICT has affecting sta | resources to provide a valuable insight into the effective use of technology in curriculum design and delivery processes. An unrivalled sourc

Figure 1: An example of how lines of text in the corpus are searched

An 'effective use of technology' is repeatedly followed by the assumption of a positive learning or assessment outcome through phrases like 'to enable and support', 'help deliver', and 'to enhance'. This was a common pattern replicated around 'use of technology' or 'the use of technology', where an exchange value for improving learning would then follow. The inference is that each gain for learning is universal and the same for everyone. However examining lines of text is really just a first step towards looking more closely at how meaning is determined by readers. Much has been written on detailed forms of linguistic analysis. Persistent, dominant discourses in education policy have already been extensively critiqued through Critical Discourse Analysis (Fairclough, 2007; Mautner, 2005; Mulderrig, 2011) though less so, in terms of educational technology policy. Studies have revealed how ideology can communicate one particular meaning in the service of power (Foucault, 1984) and marginalise others. Gramsci’s ideas on hegemony (1971) show humans internalise values from powerful prevailing social discourses. A Critical Discourse Analysis (CDA) can reveal how students, teachers, technologists and technology are positioned in a relationship of production and consumption by 'anonymous forces' (Ross, 2004: 456). To further investigate findings in my 'use' corpus, I undertook a more qualitative Critical Discourse Analysis (CDA) to examine 'Transitivity' (Halliday, 1994), which I explain below, with regard to Halliday's Systemic Functional Linguistics. There is not scope here to describe this form of analysis in detail but it considers the grammatical processes taking place in statements to locate the Participants (who), the verbal Processes (what happened) and the Circumstances (how, where, when). As a generic example, taking the statement: 'a student is learning at university' the constituent grammatical elements can be located, and named in this way:

Table 1: a generic example to show how grammatical elements are located

\begin{tabular}{|l|l|l|}
\hline A student & is learning & at university \\
\hline Participant (a noun) & Process (a verb) & Circumstances (an adverb) \\
\hline
\end{tabular}

In Table 1 a reader can be quite clear about who, the Participant (a student) is undertaking the Process (is learning) and in what Circumstance (at university) this is taking place. Each of these is labelled with their grammatical names to show if they are a noun, verb or an adverb. A key point is that this is not the only way such a statement might be written. Similar words may appear in a slightly different order of grammatical elements to reveal quite a different meaning, and conceal who exactly is involved. Taking another statement: 'universities are places of learning', when this is labelled in Table 2 the elements are not quite so apparent:

Table 2: a second generic example to show how the grammatical elements located are different

\begin{tabular}{|l|l|l|}
\hline Universities & are & places of learning (for students) \\
\hline Participant (a noun) & Process (a verb) & Participant (a noun) \\
\hline
\end{tabular}

The Participants are 'universities and 'places of learning' which are both names of things (nouns). They are connected in a relationship through 'are' which is the process (verb). To reveal any presence of a human subject, further information is required because this has not been supplied. By adding 'for students', currently in brackets,

Proceedings of the 9th International Conference on Networked Learning 2014, Edited by: Bayne S, Jones C, de Laat M, Ryberg T \& Sinclair C.
ISBN 978-1-86220-304-4 
this restores a human presence. To break down the structure of educational technology discourse, to better understand the meaning through a transitivity analysis, some new terminology needs to be introduced. In Table 3 below six broad categories of Process type (Halliday, 1994: 109-43) are identified along with examples of their meanings and their related Participants.

Table 3: Halliday's process types

\begin{tabular}{|l|l|l|}
\hline Process type & Meaning - some examples & Participants \\
\hline Material & creating, changing, doing (to), and acting & Actor, Goal, Scope \\
\hline Mental & feeling, thinking, sensing & Senser, Phenomenon \\
\hline Verbal & saying, commanding, asking, offering & Sayer, Receiver, Verbiage, Target \\
\hline Existential & existing or happening & Existent \\
\hline Relational & having attributes, identity, and symbolizing & Carrier /Attribute Token/Value \\
\hline Behavioural & behaving, smiling, yawning, laughing & Behaver/Behaviour \\
\hline
\end{tabular}

So returning once more to the first example from Table 1, when labelled in a transitivity analysis using Halliday's categories from Table 3, it would look like this:

Table 4: a Mental process type

\begin{tabular}{|l|l|l|}
\hline A student & is learning & at university \\
\hline Senser & Process: Mental & Circumstances \\
\hline
\end{tabular}

It is the Process 'is learning' that defines what kind of process type is taking place. In this case it is a Mental process, to do with thinking, therefore 'a student', as the participant, is labelled as 'Senser'. If the statement had said 'a student is talking' the labels would have been Sayer for 'a student' and the process type would have been Verbal. To demonstrate how these categories aid discussions in the educational technology community about narrow policy statements that can conceal who is acting, or missing, some example texts are discussed below.

Table 4: a Verbal process about 'the effective use of technology' conceals other labour actions

\begin{tabular}{|c|c|c|c|c|c|c|c|}
\hline The resources that were identified & \multicolumn{3}{|c|}{ confirm that } & \multicolumn{3}{|c|}{ the effective use of technology } & to enhance \\
\hline Sayer & \multicolumn{3}{|c|}{ Process: Verbal } & \multicolumn{3}{|c|}{ Receiver } & Process: Material \\
\hline \multicolumn{5}{|c|}{ assessment for learning as well as the assessment of learning } & \multicolumn{2}{|c|}{ can improve } & \\
\hline \multicolumn{5}{|c|}{ Goal } & \multicolumn{2}{|c|}{ Process: Material } & \\
\hline \multicolumn{2}{|c|}{ the effectiveness of teaching approaches } & and & \multicolumn{3}{|c|}{ enhance } & \multicolumn{2}{|c|}{ the student learning experience } \\
\hline \multicolumn{2}{|c|}{ Goal } & & \multicolumn{3}{|c|}{ Process: Material } & \multicolumn{2}{|c|}{ Goal } \\
\hline
\end{tabular}

What then might be learned from these categories and why might this be considered a deceptively spacious discourse? In Table 4 above, 'nominalisation' occurs. This is where nouns can affect meaning when they stand in for verbal processes (Phillips \& Jorgensen, 2002: 83). A common effect is a reduction in human agency. It becomes hard to detect who exactly this proposition refers to, or who has declared it to be so. In this case, 'the resources that were identified' take the place of the labour actions of a person, as they 'confirm' the rest of the statement. 'The resources that were identified' is labelled as Sayer because a Verbal process follows this in 'confirm that'. Looking at what comes next, it is 'the effective use of technology' that the wording suggests is 'to enhance' assessment and 'can improve' 'the effectiveness of teaching approaches'. There are two instances of the Material process 'to enhance'. After the first of these, 'assessment for learning as well as the assessment of learning' is the universal Goal. After the second 'enhance' the final Goal is 'the student learning experience'. The preceding 'the' earmarks students as if they all experience assessment in the same way, not in diverse contexts as individuals. It also places students at the very end of a long statement that begins with 'the resources' determining what follows. So we cannot really identify any of the decision makers in this statement that, at the end, claims to 'enhance the student experience'. In summary, liberal sounding policy when broken 
down in this way can help reveal the hidden agendas of economic improvement, but these quickly become detached from the social and political choices - and indeed the human beings who made these.

Table 5: 'the Strategy' undertakes this Verbal process

\begin{tabular}{|l|l|l|l|}
\hline The Strategy & proposes & to enhance & the learning opportunities of all learners \\
\hline Sayer & Proc: Verbal & Proc: Material & Receiver \\
\hline
\end{tabular}

through the appropriate use of elearning

Circumstances

In Table 5, there is a more hierarchical statement. 'The Strategy' is labelled the Sayer again because a Verbal process follows in the word 'proposes'. Once more, nominalization prevents the establishment of human agency. 'The Strategy' surely cannot determine all these things for us, can it? Looking carefully at the Receiver (or goal) that the Strategy proposes to enhance, it is all encompassing, suggesting positive change to 'the learning opportunities for all learners'. This cannot be the case for all, but there is also a context which defines this expectation within what is described as 'the appropriate use of elearning'. Whilst sounding common sense, readers have no further information to know the confines of 'the appropriate use'. This is a phrase that is used often in my corpus, but remains ambiguous. It may hold fast the values of a neoliberal economy, or we as a community, might understand 'appropriate use of elearning' as a critical space we might re-occupy, in order to bring a more diverse account from the educational community. To do so, people would need to reconsider the tendency in policy discourse to place 'the' before 'appropriate use' and instead promote more explicit accounts of who it is that really proposes something rather than hide behind a strategy. If we do not, we simply reinforce a deterministic approach that allows one universal blueprint for educational technology to persist.

Table 6: a relational process about technology conceals other labour actions

\begin{tabular}{|l|l|l|}
\hline The key aims of the TEL Strategy & are & to ensure that technology is used \\
\hline Value & Proc: Relational/Identifying & Token \\
\hline
\end{tabular}

\begin{tabular}{|l|l|l|}
\hline appropriately, effectively and efficiently & to support & student learning and development; \\
\hline & Proc: Material & Goal \\
\hline
\end{tabular}

\begin{tabular}{|l|l|l|l|}
\hline support & staff in the delivery of the curriculum; & prepare & students \\
\hline Proc: Material & Goal & Proc: Material & Goal \\
\hline
\end{tabular}

\begin{tabular}{l|l|l|}
\hline to function & in a technologically-rich and changing world; & enhance \\
\hline Proc: Material & Goal & Proc: Material \\
\hline
\end{tabular}

In the final example above in Table 6, a Relational Identifying process is shown. 'The key aims of the TEL Strategy' are labelled as the Value. Through the Relational process 'are' this is identified by the Token: 'to ensure that technology is used appropriately, effectively and efficiently'. The Token refers to the participant in the clause that embodies the other concept, or represents it. The other concept may be something more general and is labelled as Value. A Relational/identifying process is also reversible and as such is rather like placing an equals sign between two concepts. It might look like this:-

'The key aims of the TEL Strategy' = 'to ensure that technology is used appropriately, effectively and efficiently'

In a sense this statement could be said to be complete if it stopped here. The main agenda has been stated. Yet the text continues on, and slowly reveals the many labour actions that are overshadowed by this first part of the Relational clause. The full term of Technology Enhanced Learning is not mentioned. Instead a TEL Strategy condenses this meaning. However, the key aims are clearly linked to a belief by policy makers that this is what a Strategy for TEL represents: technology is used appropriately, effectively and efficiently. The strategy should ensure it, but who decides what this use of technology looks like and feels like in the multiplicity of practice? 
Reading further along, there are human labour actions that are intended 'to support' and 'prepare' students and staff, but ultimately the agenda of improvement is related to exploiting 'new market opportunities'. Whilst universities need to remain viable, what is deemed appropriate use of technology for student and staff learning should not be confined within 'new market opportunities'.

\section{The technology-language-learning nexus}

Critical Discourse Analysis has sometimes been criticised for putting forward only negative representations of texts and ideologies (Breeze, 2013). However such analysis is not only an empowering approach to reveal ways that language may restrict conceptual space, it also provides a discursive opportunity for new possibilities to learn and move on from a deceptive space. If educational technology has been 'enframed' (Heidegger, 1977) in policy texts, through an ideology of false consciousness or a hegemony of 'common sense' (Gramsci, 1971) then, through CDA, we might demonstrate these restrictions. This can however lead to a point where it is hard to move forward beyond having identified what seems to be 'going on'. We have exposed an ideology, now what can be done? Van Dijk provides a route back to a more plural understanding of 'ideology' which is helpful in seeking new dialogues. Emphasising ideology more broadly in terms of 'belief systems' (van Dijk, 2011), allows a distinction between these social beliefs, shared by members of social groups and their manifestations into ideological practices (van Dijk, 2011). These ideas remind us that a dominant ideology need not remain 'fixed'. To avoid closure in language and keep plural routes for networked human relationships visible may involve conscious decisions in how we each speak and write about technology, in language about learning.

In conclusion, a brief critical appraisal of the connections between technology, language and learning helps to contextualise the methodology. The idea for linking these specific elements comes from the construction of the term Technology Enhanced Learning. It positions technology, language and learning in an instrumental but ambiguous form that humans have little part in. These are three words that could mean creative learning through a use of technology, yet on the other might simply provide another useful neoliberal policy vehicle to further the opinion that new technologies, in themselves, determine learning. Networked Learning too has been the victim of such ambiguities in policy, discussed often in terms of efficiency and technical issues, less as a political choice (Jones, 2002). With these debates in mind, I propose that connections between technology, language and learning are dialectical (Fairclough, 2007) and mutually constitutive (Wajcman, 2002) in shaping how learners experience new media across personal networks, in relationships of power and ideology, but also of possibility. In forthcoming work I call this a technology-language-learning nexus and suggest this is a broader critical base to theoretically differentiate educational technology and resist simplistic, linear determinism in language. If perceptions of technology for learning have become distorted through 'the logics of profit and domination' (Matthewman, 2011: 38) through neoliberal discourse (Jessop, 2008; Sennett, 2006), more critical pedagogies (Freire, 1969) provides 'counterlogics' (McLaren, 1994a) to such linear approaches. If learning is essentially about change, then a static and stale deterministic model repeated is not likely to easily connect with progressive ideas for Networked Learning. Yet 'technological determinism is a constant risk' (Enriquez, 2012:328). If the last decade of policy continuities has too easily dispensed with the tentacles of history, in a tireless series of 'makeovers' to improve and transform terminology to meet deterministic economic demands, now is a good time to transcend the limitations of conventional thinking. Radical rethinking means addressing the language we use as a network of relations to avoid a continuation of 'existing assumptions under a different name' (Hall, Massey, and Rustin, 2013).One idea need not subsume another. Instead each may support the other within a critical awareness of a technology-language-learning nexus. This informs a broader theoretical underpinning for educational technology, as part of a cooperative and trans-disciplinary endeavour.

\section{References}

Andrews, R. (2011). Does e-learning require a new theory of learning? Some initial thoughts. Journal for Educational Research Online/Journal für Bildungsforschung 3(1), 104-121.

Baker, P. (2006). Using Corpora in Discourse Analysis. London: Continuum.

Braudel, F (1985). Civilisation and Capitalism 15th - 18th Century: The Structures of Everyday Life: The limits of the Possible, Vol 1. London: William Collins Sons and Co.

Breeze, R. (2013). Critical discourse analysis and its Critics. Pragmatics, 21(4).

Campbell, J. L., \& Pedersen, O. K. (Eds.). (2001). The rise of neoliberalism and institutional analysis. Princeton University Press.

Conole, G. C., \& Oliver, M. (2002). Embedding theory into learning technology practice with toolkits. Journal

Proceedings of the 9th International Conference on Networked Learning 2014, Edited by: Bayne S, Jones C, de Laat M, Ryberg T \& Sinclair C.
ISBN 978-1-86220-304-4 
of Interactive Media in Education, 2002(1).

Dahlberg, L. (2004). Internet research tracings: Towards non-reductionist methodology. Journal of Computer Mediated Communication, 7 (1). http://jcmc.indiana.edu/vol7/m issue1/dahlberg.html [Viewed 24/9/13]

Enriquez, J. (2012). Being (t) here: mobilising 'mediaspaces' of learning. Learning, Media and Technology, 38:3, 319-336.

Fairclough, N. (2007). Global capitalism and change in Higher Education: dialectics of language and practice, technology, ideology. In BAAL conference: Edinburgh.

Feenberg, A. (2003): What Is Philosophy of Technology? http://www.sfu.ca/ andrewf/komaba.htm [Viewed 24/9/13]

Foucault, M. (1984). Power/knowledge. New York: Pantheon.

Freire, P. (1969). Pedagogy of the oppressed. New York: Continuum.

Giroux, H. a. (1992) Border crossings. New York. Routledge

Goodyear, P., Hodgson, V. and McConnell D. (2004) Research on networked learning: An overview. In Goodyear, P., Banks, S., Hodgson, V., McConnell, D (Eds) Advances in Research on Networked Learning, Dordrecht: Kluwer Academic Publishers

Gramsci, A (1971). Selections from the Prison Notebooks. London: Lawrence \& Wishart.

Greener, I., \& Perriton, L. (2005). The political economy of networked learning communities in higher education. Studies in Higher Education, 30(1), 67-79.

Hall, S., Massey, D., \& Rustin, M. (2013). After neoliberalism: analysing the present. Soundings, 53(53), 8-22.

Halliday. M.A.K (1994). An introduction to functional grammar. 2nd ed..London: Arnold

Harvey, D. (2005). A Brief History of Neoliberalism. Oxford: Oxford University Press.

Heidegger, M (1977). The Question Concerning Technology and Other Essays. New York, London: Garland Publishing, Inc.

Hoey. M (1991). Pattern of Lexis in Text. Oxford: Oxford University Press.

Hunston, S (2002). Corpora in Applied Linguistics. Cambridge: Cambridge University Press

Jessop, B (2008). The Knowledge Based Economy. Article prepared for Naked Punch. http://www.nakedpunch.com/ [Viewed 3/10/13]

Joint Information Systems Committee (2009) Effective practice in a digital age. http://www.jisc.ac.uk/publications/programmerelated/2009/effectivepracticedigitalage.aspx [Viewed $1 / 10 / 13]$

Joint Information Systems Committee (JISC) (2012) JISC Strategy 2010-2012 http://www.jisc.ac.uk/aboutus/strategy/strategy1012/context.aspx [Viewed 1/10/13]

Jones, C. (2002). Is there a policy for networked learning? In Proceedings of the Networked Learning 2002 Conference, 26-28 March 2002, Sheffield, UK.

Jones, C. (2012). Networked learning, stepping beyond the Net Generation and Digital Natives. In Exploring the Theory, Pedagogy and Practice of Networked Learning (pp. 27-41). Springer New York.

Lash, S (2002). Critique of information. London: Sage

Latour, B (1992). Where are the missing masses? The sociology of a few mundane artifacts. Shaping technology/building society: Studies in sociotechnical change, 225-258

Marcuse, H (1964). One-Dimensional Man: Studies in the Ideology of Advanced Industrial Society London: Routledge

Marx, K. (1867) Capitalism and the modern labour process. Capital, volume 1. In Scharff, R. C., \& Dusek, V. (eds). (2003). Philosophy of technology: The technological condition: An anthology. Oxford, UK: Blackwell

Massey, D. (2013). Vocabularies of the economy. Soundings, 54(54), 9-22. http://www.lwbooks.co.uk/journals/soundings/contents.html [Viewed 1/10/13]

Matthewman, S (2011). Technology and Social Theory. New York, NY: Palgrave.

Mautner, G. (2005). The entrepreneurial university: A discursive profile of a higher education buzzword. Critical Discourse Studies, 2 (2), 95-120.

McLaren, P (1994a) Life in Schools. New York: Longman

McLuhan, M. (2005) Understanding Media: Lectures and Interviews. Cambridge, MA: MIT Press.

Mulderrig, J.(2011). The Grammar of Governance, Critical Discourse Studies 8 (1), 45-68

Parchoma, G., \& Keefer, J. M. Transdisciplinary research in technology enhanced/networked learning practices Proceedings of the 8th International Conference on Networked Learning 2012, Edited by: Hodgson V, Jones C, de Laat M, McConnell D, Ryberg T \& Sloep P

Ross, P (2004): Globalization and the closing of the universe of discourse: the contemporary relevance of Marcuse's Marxism , The European Legacy: Toward New Paradigms, 9 (4) 455-467

Rustin, M. (2013). A relational society. Soundings, 54(54), 23-36. 
http://www.lwbooks.co.uk/journals/soundings/contents.html [Viewed 1/10/13]

Scott, M. (1997). PC analysis of key words—and key key words. System, 25(2), 233-245

Sennett, R. (2006). The culture of the new capitalism, Yale University Press

Sezneva, O. (2007) We Have Never Been German: The Economy of Digging in Russian Kaliningrad in C.

Calhoun and R. Sennett (eds) Practicing Culture (pp. 13-34). Abingdon: Routledge

Sørensen, E. (2009) The materiality of learning: Technology and knowledge in educational practice. New York, NY: Cambridge University Press.

Van Dijk, T. A. (Ed.). (2011). Discourse studies: A multidisciplinary introduction. Sage.

Wajcman, J (2002). Addressing Technological Change: the challenge to social theory, Current Sociology, 50 (3), 347-63.

Williams, R (1980) “Base and superstructure in Marxist cultural theory.” In Problems in Materialism and Culture: Selected Essays, (pp. 31-49). London: Verso and NLB 